1895. Mille huit cent quatre-vingt-quinze

Revue de l'association française de recherche sur

I'histoire du cinéma

$91 \mid 2020$

Ivresse patrimoniale ? - Décors d'Intolérance -

Germaine Dulac - Alice au pays des merveilles - Éric

Rondepierre

\title{
Joxean Fernández (dir.), Cinéma basque. Trois générations de cinéastes
}

\section{Stéphanie E. Louis}

\section{OpenEdition}

\section{Journals}

Édition électronique

URL : https://journals.openedition.org/1895/8108

DOI : $10.4000 / 1895.8108$

ISSN : $1960-6176$

Éditeur

Association française de recherche sur l'histoire du cinéma (AFRHC)

Édition imprimée

Date de publication : 1 juin 2020

Pagination : 198-200

ISBN : 978-2-37029-091-5

ISSN : 0769-0959

Référence électronique

Stéphanie E. Louis, « Joxean Fernández (dir.), Cinéma basque. Trois générations de cinéastes 》, 1895. Mille huit cent quatre-vingt-quinze [En ligne], 91 | 2020, mis en ligne le 10 mai 2021, consulté le 01 juin 2021. URL : http://journals.openedition.org/1895/8108; DOI : https://doi.org/10.4000/1895.8108

Ce document a été généré automatiquement le 1 juin 2021.

(c) AFRHC 


\title{
Joxean Fernández (dir.), Cinéma basque. Trois générations de cinéastes
}

\author{
Stéphanie E. Louis
}

\section{RÉFÉRENCE}

Joxean Fernández (dir.), Cinéma basque. Trois générations de cinéastes, Urugne, Artez, 2019,399 p.

Depuis 1978, la Filmoteca vasca-Euskadiko filmategia préserve, conserve et diffuse le cinéma basque et Joxean Fernández, coordinateur de la présente publication, est arrivé à sa direction en 2010. Auparavant maître de conférences d'espagnol à l'université de Nantes, il a soutenu une thèse en 2006 sur «Cinéma et guerre civile au pays basque (1936-1939) ». Quelques-unes de ses initiatives tendent à resserrer les liens avec le côté français du pays basque. Ainsi remarquera-t-on en 2019, une rétrospective de Yannick Bellon, cinéaste née à Biarritz, avec publication d'un opus en espagnol pour accompagnement (Éric Le Roy, Yannick Bellon. La Mirada de frente, Donostia/San Sebastián, Euskadiko filmategia-Filmoteca vasca, 2019, 307 p.). L'ouvrage dont il sera ici question apparaît comme un autre signe de cette volonté de rapprochement, car c'est la traduction d'un volume déjà publié en basque et en espagnol en 2015. À quatre ans d'intervalle, la version française propose un article supplémentaire qui rend compte des différents facteurs d'un épanouissement sans précédent du cinéma basque depuis lors.

2 Le reste des contributions, hormis le propos liminaire de Joxean Fernández, constituent les actes d'un congrès tenu en juillet 2014 dans le cadre des cours d'été de l'Université du Pays Basque. Profitant de l'opportunité que «trois générations de cinéastes basques encore en activité » (p. 9) puissent venir témoigner, il s'agissait de fournir des éléments d'interprétation de leurs expériences en valorisant les recherches, des plus anciennes aux plus récentes, sur cette cinématographie " périphérique " - selon l'expression de Santos Zunzunegui dans son incontournable étude, El cine en el País Vasco : la aventura de 
una cinematografía periférica (Filmoteca Regional, Murcia, 1985). Joxean Fernández précise: "la participation généreuse des cinéastes est devenue la véritable colonne vertébrale du Congrès et de la publication qui s'en est suivie » (p. 10). Il s'agit donc d'un projet d'histoire du temps présent tout autant que d'histoire du cinéma. Les trois générations amenées à témoigner sont celles qui accédèrent à la réalisation de longs métrages après la dictature franquiste.

3 En amont de la transcription de la table ronde dédiée aux cinéastes de la fin des années 1970-années 1980, un premier ensemble de textes expose en profondeur les prolégomènes de ce projet scientifique. Santos Zunzunegui revient sur la notion de cinéma basque, puis Susana Torrado Morales livre un état de la recherche sur cette cinématographie. Kepa Sojo évoque les cinéastes des années 1960-1970, et Jesús Angulo ceux des années 1980. Entre temps, Andoni Elezcano et Josu Martínez présentent leurs récentes redécouvertes de deux films-clés de l'histoire du cinéma basque : Sinfonía vasca (Adolf Trotz, 1936), le dernier qui fut tourné en terre basque avant la guerre civile, et Gure sor lekua (André Madré, 1956), premier long métrage tourné intégralement langue basque. Zigor Etxebeste analyse, quant à lui, l'évolution de l'usage de l'euskara dans les films.

4 La table ronde "Première génération » réunit Montxo Armendáriz, Ana Díez, Pedro Olea et Imanol Uribe. En conclusion, Santiago de Pablo aborde les rapports entre cinéma et identité nationale dans le Pays basque du $\mathrm{xx}^{\mathrm{e}}$ siècle. Carlos Roldán enchaîne sur l'«éclosion des talents» caractéristique des années 1990. Casilda de Miguel et Iratxe Fresneda s'attachent respectivement au traitement du féminin dans les films basques et aux femmes cinéastes basques. La place du cinéma d'animation (Begoña Vicario, Maitane Junguitu) et la question des expérimentations formelles (Antonio Santamaria) sont aussi abordées, alors que Rob Stone interroge les liens entre cinéma et citoyenneté. La diffusion du cinéma basque au festival international de Donostia/ Saint-Sébastien est traitée par Maialen Beloki. La table ronde " Deuxième génération » réunit Juanma Bajo Ulloa, Daniel Calparsoro, Helena Taberna et Enrique Urbizu.

On entre ensuite de plain-pied dans la dernière période traitée par ce volume: le $\mathrm{xxI}^{\mathrm{e}}$ siècle, avec en préambule, un bilan de Kimuak, programme de promotion des films courts lancé en 1998, et désormais étendu aux longs métrages. La table ronde "Troisième génération» donne la parole à Koldo Almandoz, Asier Altuna, Borja Cobeaga, Jose Mari Goenaga, Isabel Herguera et Pablo Malo. Patxi Azpillaga analyse ensuite, du point de vue économique, les difficultés auxquelles se confronte un projet audiovisuel en terre basque. Il modère également la quatrième table ronde, consacrée à l'industrie cinématographique basque avec les producteurs Xabier Berzosa, Carlos Juárez, Aintzane Pérez del Palomar, Joxe Portela, Koldo Zuazua. Les cas des productions transnationales récentes (María Pilar Rodríguez) et de l'audiovisuel underground (Victor Iriarte) ainsi que l'évolution des politiques culturelles en faveur cinéma basque depuis 2015 (Miren Manias) viennent compléter cet état des lieux, avant une ultime table ronde dédiée à la critique cinématographique.

6 De nombreuses illustrations, toutes en couleurs, ponctuent les articles et transcriptions d'échanges. Des biographies des cinéastes et auteurs sont proposées en fin d'ouvrage, permettant de mieux les situer. La forme du livre souligne la place centrale du témoignage autant que la volonté d'établir le dialogue entre acteurs et chercheurs. De prime abord, la répartition des contributions peut surprendre: alors que les deux premiers ensembles d'articles sont assez importants, ils se font plus rares dès lors que 
l'on aborde les années les plus récentes. Ainsi, dans ce que l'on pourrait considérer comme la dernière partie de l'ouvrage, relative à l'entrée dans le xxI siècle, trois tables rondes se succèdent qui, articulées aux contributions sur l'économie, la politique et les tendances de la production actuelle, dressent le panorama complet des «mondes" (H.S. Becker) du cinéma basque. L'ouvrage parvient finalement à une conjonction réussie entre témoignages et analyses, offrant un ensemble à la fois riche et original. Il complète bien les publications qui lui sont sensiblement contemporaines comme Basque Cinema : a Cultural and Political History, de Rob Stone et María Pilar Rodríguez (Londres, I.B. Tauris, 2015), d'ailleurs publié en espagnol la même année. L'objectif de se poser comme un titre de référence semble donc tout à fait rempli. 